\title{
Intentional learning and retention of words following various orienting tasks
}

\author{
PETER C. P. CHOW, JANICE L. CURRIE, and FERGUS I. M. CRAIK \\ Erindale College, University of Toronto, Mississauga, Ontario, Canada L5L IC6
}

\begin{abstract}
An interesting puzzle is provided by previously reported results showing that retention levels following performance of "shallow" orienting tasks are little enhanced by intentional learning instructions. The present results show that lack of processing time does not underlie this failure. Retention was enhanced only when ample processing time and/or a beneficial task was explicitly given to subjects. It is concluded that young adults do not possess great insight into their learning processes.
\end{abstract}

Over the past 6 years, many studies have provided support for the levels-of-processing approach to memory (Craik \& Lockhart, 1972). The basic point of that approach is that retention is a function of the "depth," or qualitative type, of processing carried out on the event when it is perceived; specifically, that greater degrees of semantic processing are associated with higher levels of performance. In a typical experiment, subjects are induced to process words to shallow or deep levels of analysis by means of orienting tasks (Craik \& Tulving, 1975; Hyde \& Jenkins, 1973). Thus, for example, the word DOG might be presented to different groups of subjects with the questions "Is the word in capital letters?", "Does the word rhyme with log?", or "Is the word a kind of animal?" In subsequent retention tests, both recognition and recall show large increases from the structural task (case judgment) to the semantic task.

One intriguing puzzle arising from this work is that exactly the same pattern of results has been found regardless of whether the orienting task was given under incidental or intentional learning conditions (Craik, 1977, Experiment 2; Craik \& Tulving, 1975; Hyde \& Jenkins, 1973). Why is it that subjects performing the shallow structural task under intentional learning conditions do not carry out further processing in order to enhance their recall? The differences in retention between structural and semantic conditions is not trivial; for example, Craik (1977, Experiment 2) found that the percentage of words recognized varied from $22 \%$ to $86 \%$ under intentional learning conditions, depending on whether the orienting task was structural or semantic.

The present article reports an investigation of two possible reasons for the poor retention of words following performance of a shallow orienting task under intentional learning conditions. The first possibility is that subjects simply did not have enough time to carry

The experimental work reported here was supported by Grant A8261 from the National Research Council of Canada to the third author. Requests for reprints should be sent to F. I. M. Craik, Erindale College, Mississauga, Ontario, Canada L5L 1C6. out more beneficial coding of the word; perhaps perceiving each word, noting its structural characteristics and checking these on the answer sheet filled the time allowed. A second, and more interesting, possibility is that subjects have rather little insight into what mental operations will lead to good or poor retention. If this is so, then subjects performing the structural task might feel that they had clearly perceived the word and that this degree of perception would be sufficient to support later retention. In line with this view, Cutting (1975) showed that after subjects performed incidental orienting tasks, they were quite poor at predicting how many words they would recall.

These ideas were evaluated in the present study. Subjects were required to process words differently by means of three orienting tasks. Learning was intentional in all conditions; that is, subjects knew that the main point of the experiment was to remember the words. The possibility that insufficient processing time is the reason for poor retention was tested by presenting the task at either a moderate rate $(6 \mathrm{sec} /$ word $)$ or a slow rate (12 sec/word). The possibility that subjects do not realize that shallow encoding is insufficient to support good retention was tested by giving one group of subjects a brief lecture on effective encoding techniques, and by explicitly presenting a second group of subjects with a semantic task to perform in addition to their primary orienting task. Since it is possible that the factors of processing time and processing strategy interact (e.g., subjects may not be able to carry out further processing unless they have sufficient time), the two factors were combined orthogonally in the present experiment.

\section{METHOD}

Seventy-two undergraduate students from Erindale College were paid for their participation in the experiment. They were randomly assigned to one of six groups of 12 subjects. Each subject saw the same list of 60 common nouns (Craik \& Tulving, 1975, Appendix 1) presented on a television screen, one at a time. In the fast conditions, each word was exposed for $4 \mathrm{sec}$, with a 2-sec interword interval during which asterisks appeared; 
in the slow conditions, each word appeared for $8 \mathrm{sec}$ with a 4-sec interword interval.

Each subject had his or her own list of 60 typed questions corresponding to the 60 presented words. The questions concerned typescript (e.g., “capital letters?"), rhyme (e.g., "rhymes with LOG?"), or semantic category (e.g., "a type of fruit?"). There were 20 questions of each type and, of these, 10 yielded a positive answer and 10 a negative answer. Subjects checked "yes" or "no" on their typed question sheets to record their answers to the orienting task questions. All subjects saw the same 60 words in the same sequence, but six different question formats were constructed such that all six possible questions (case, rhyme, category by yes or no) were asked for each presented word across different subjects. Question types were distributed randomly through the list.

All subjects were informed of the final recall and recognition tests. They were instructed to study the question during each interword interval, then to answer yes or no by checking "+" or "-" on their answer sheets after the word appeared. The six experimental conditions are referred to as F1, F2, F3, S1, S2, and $S 3$, with $F$ and $S$ indicating fast and slow, respectively. Subjects in Conditions F1 and S1 were instructed to learn every word after they had answered the corresponding question. Subjects in F2 and S2 were given the same instruction, plus a brief lecture on the levels-of-processing effect; it was suggested that they should use semantic encoding for every word by generating an adjective that described the word after they had answered the orienting task question. Subjects in F3 and S3 received the same lecture as did subjects in Condition 2, but instead of the instruction to generate adjectives, they were provided with an additional sentence frame (with one missing word) for each presented word and were required to judge on a 4-point scale how well the presented word fit the sentence frame, where 1 was considered to be least appropriate and 4 was considered to be very appropriate. Each sentence frame was constructed in such a way that when the presented word was inserted, it created a meaningful sentence. The purpose of this additional task was to force the subjects to use semantic coding for every presented word.

Prior to the 60 experimental trials, all subjects were given 10 practice trials in order to familiarize them with the experimental procedure. After the 60 encoding trials, subjects were given $10 \mathrm{~min}$ to recall all the presented words in any order. Following the recall task, a recognition test was administered. The test consisted of two sheets containing 180 words: the original 60 words and 120 distractors, mixed randomly. The subjects were asked to check exactly 60 words: those they had seen on the television screen.

\section{RESULTS}

The results from Conditions 1, 2, and 3 are shown in Figures 1, 2, and 3, respectively. The recall data will be examined first. Overall, several main effects were found that have been obtained in many previous studies and are of little interest here. These main effects are as follows: The slower rate of presentation resulted in higher levels of recall; also, higher recall levels were found for words associated with positive responses to the orienting questions compared with "negative response" words. Finally, an overall "levels" effect was found; that is, semantic processing was generally superior to phonemic and structural processing. All three effects were significant beyond $p<.001$ in an analysis of variance. The overall effect of instructional condition was also significant, although the effect was surprisingly
CONDITION 1

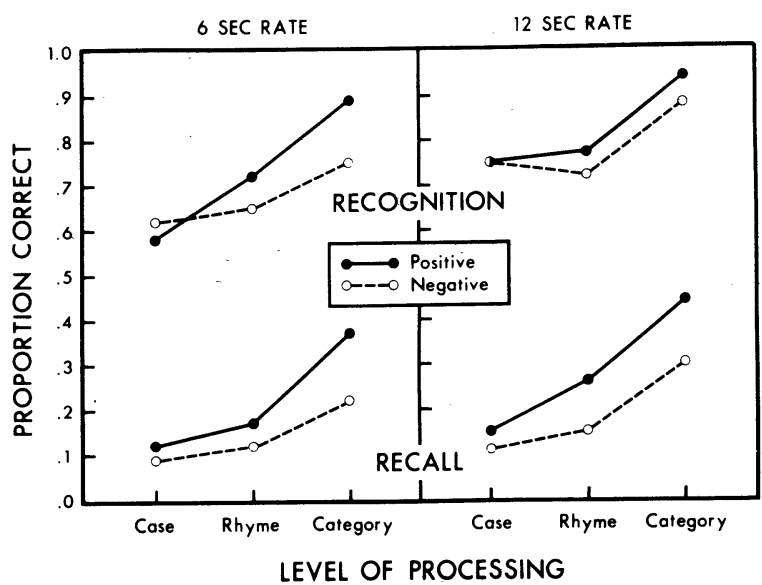

Figure 1. Recognition and recall levels in Condition 1 (intentional learning).

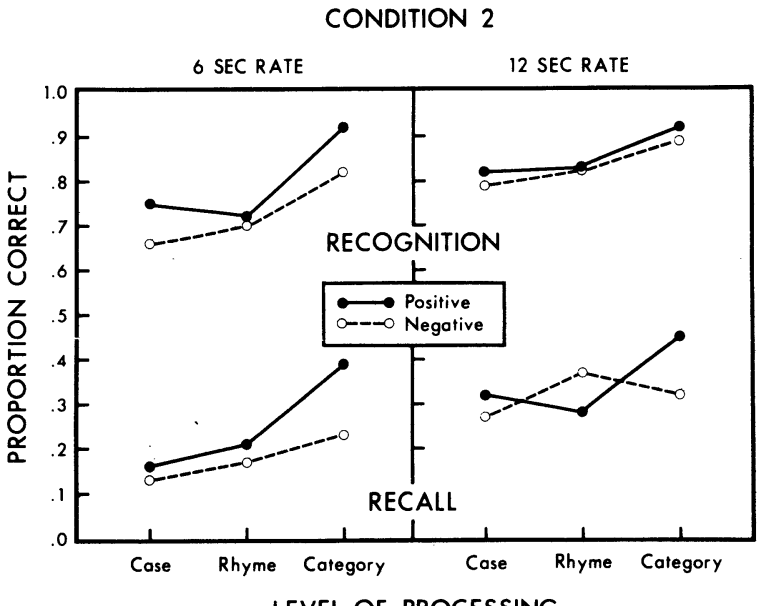

Figure 2. Recognition and recall levels in Condition 2 (intentional learning plus instructions to generate adjectives).

\section{CONDITION 3}

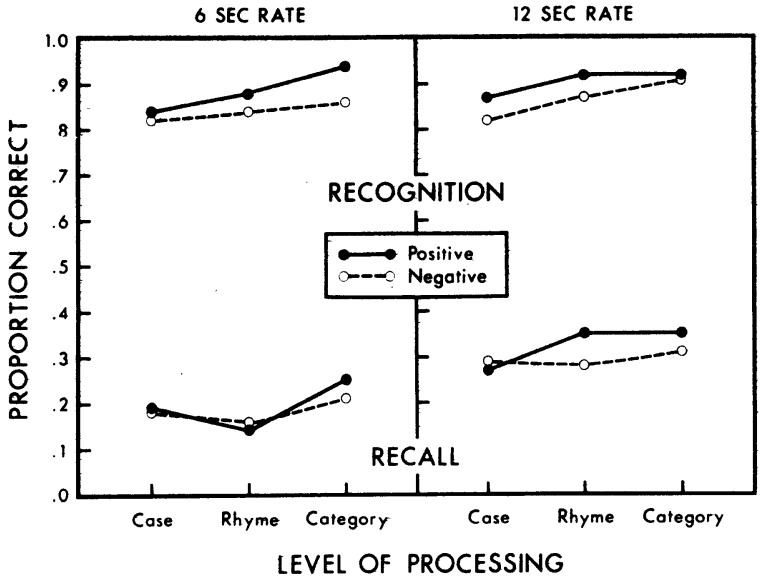

Figure 3. Recognition and recall levels in Condition 3 (intentional learning plus sentence completion task). 
small $[F(2,66)=3.19, p<.05]$. The main interaction of interest was that between orienting task and instructional condition; this interaction was significant $[F(4,132)=5.39, p<.001]$. Figures $1-3$ show that the interaction is attributable to a reduction in the levels effect from Condition 1 to Condition 3.

However, the main point of the experiment was to ascertain under which conditions the levels effect was eliminated, and this was assessed by carrying out analyses of variance within each experimental condition. Figure 1 shows that the different orienting tasks were associated with different recall levels, both at the fast and the slow rates $[\mathrm{F}(2,22)=17.7, \mathrm{p}<.001$, and $F(2,22)=22.5, p<.001$, respectively]. Thus, even when ample encoding time was provided, subjects did not encode structural and phonemic words in a way that led to recall at the level of semantic words. In Condition F2, shown in Figure 2, the levels effect was significant $[F(2,22)=12.6, p<.001]$; however, the levels effect was not significant at the slow rate (S2) $[F(2,22)=2.07, p>.10]$. Thus instructions to generate appropriate adjectives was beneficial to poorly encoded words only when the subject had ample time to carry out the additional encoding. By contrast, Figure 3 shows that the levels effect was eliminated at both rates of presentation $[F(2,22)=2.66, p>.05$, and $F(2,22)=1.16, p>.10$, for $F 3$ and $S 3$, respectively] . Thus when the additional semantic encoding was explicitly provided, subjects could utilize it, even at the fast rate. The recall levels are very low in F3, probably because subjects were so pressed for time doing both tasks in $6 \mathrm{sec}$ that they had no further time to organize words for recall. Note, however, that the beneficial effects of the two encodings does show in the high level of performance in the recognition task.

The recognition data, also given in Figures 1, 2, and 3 , show essentially the same pattern of results. An overall analysis of variance yielded significant effects of experimental condition (Condition $3>2>1$ ), rate of presentation (slow $>$ fast), level of processing (semantic $>$ phonemic $>$ structural), and response type (positive $>$ negative) (all beyond the $p<.001$ level). The interaction between condition and level was significant $[F(4,132)=3.68, p<.01]$, again showing that the levels effect was modified by the instructional conditions. In Condition 1, the levels effect was significant at both fast and slow rates $[\mathrm{F}(2,22)=13.8, \mathrm{p}<.001$ and $\mathrm{F}(2,22)=7.53, \mathrm{p}<.01$, respectively]. In Condition 2 the levels effect was again significant at both fast and slow rates $[\mathrm{F}(2,22)=12.73, \mathrm{p}<.001$, and $\mathrm{F}(2,22)=4.43, \mathrm{p}<.05$, respectively]. In Condition 3 , however, the levels effect was not significant at either rate. Thus the pattern of results in recognition was the same as that in recall, except that the levels effect in Condition 2-slow (S2) was significant in recognition but not in recall. Numerically, the effects were roughly equivalent; however, the difference in retention levels between structural and semantic processing conditions was $9 \%$ for recall and $10 \%$ for recognition.

\section{DISCUSSION}

We would like to make several points from the data presented above. First, the results in Condition F1 confirmed previous findings showing markedly better retention of words following a semantic orienting task than following a structural orienting task, even when subjects were fully aware that recall and recognition would be tested. Second, Condition S1 showed that the levels effect was not due simply to insufficient processing time; subjects in $S 1$ had $12 \mathrm{sec} /$ word, yet the relatively poor performance following structural processing was just as evident in $\mathrm{S} 1$ as it was in F1. Thus the finding of a levels effect under intentional learning conditions cannot be attributed to a shortage of time. Third, when a moderate constraint was placed on subjects to carry out additional semantic processing, in all cases (Conditions F2 and S2) the constraint greatly attenuated the levels effect when the presentation rate was very slow (S2) but failed to modify the effect substantially at the faster presentation rate. Fourth, the levels effect was eliminated in both recognition and recall, and at both rates of presentation, when subjects were explicitly given a semantic task to perform in addition to their primary orienting task.

In line with many previous investigators, we conclude that time by itself is not an important factor for learning and memory; it is the nature of the processing carried out that is critically important (Postman, 1964). It seems likely that the extra learning time provided in Condition S1 was used by subjects for rote, maintenance rehearsal that had little further beneficial effect on later retention (Rundus, 1977). In Condition 2, where subjects were encouraged to generate descriptive adjectives, the retention of words following structural and phonemic tasks was enhanced at the slow rate only. Apparently, subjects have some difficulty switching to a second task unless they are given ample time. When the task was explicitly provided in Condition 3, however, the "shallow" encodings benefited at both rates of presentation. Finally, it may be noted that the superiority of positive over negative responses declined from Condition 1 to Condition 3. This finding is in line with the idea that in Condition 3 it is the second task that is supporting performance, and thus response type on the first task becomes largely irrelevant.

To return to the main point of the study, can we conclude anything about why intentional learning instructions have such a surprisingly small effect on retention following performance of orienting tasks? The present data suggest two reasons: First, that subjects are rather poorly aware of the mental processes necessary to support good retention; and, second, that beneficial extra processing is somewhat effortful to undertake. The first conclusion follows from the comparatively slight improvement in performance from Condition $\mathrm{F} 1$ to Condition $\mathrm{S} 1$; the second conclusion follows from the finding that extra processing takes place only if ample time or highly specific guidance is provided.

The notion of a lack of insight into the mental processes necessary for remembering accords with Cutting's (1975) findings and suggests that the conclusions regarding the limited knowledge children possess about their mnemonic processes (e.g., Flavell, Note 1) can be extended to adults placed in certain learning situations. When given an ineffective orienting task to perform under intentional learning conditions, it seems that "subjects do not know what to do or simply do not change what they are doing without the demands of a specific task" (Jenkins, 1974 , p. 16). This conclusion must be qualified by Postman and Kruesi's (1977) finding that subjects' retention levels were high following a structural orienting task provided that the importance of the memory test was strongly emphasized. Nonetheless, in the present studies and others, bright young adult 
subjects failed to switch in effective learning processes unless very explicit guidance was given. It seems clear that young adults do not have extensive insight into their learning processes, and that there is scope for further metacognitive development in adult life.

\section{REFERENCE NOTE}

1. Flavell, J. Metacognitive development. Paper presented at the NATO Advanced Study Institute on Structural/Process Theories of Complex Human Behavior, Banff, Alberta, Canada, 1977.

\section{REFERENCES}

CrAIK, F. I. M. Depth of processing in recall and recognition. In S. Dornic (Ed.), Attention and performance VI. Hillsdale, N.J: Lawrence Erlbaum, 1977.

Craik, F. I. M., \& Lockhart, R. S. Levels of processing: A framework for memory research. Journal of Verbal Learning and Verbal Behavior, 1972, 4, 671-684.
Craik, F. I. M., \& Tulving, E. Depth of processing and the retention of words in episodic memory. Journal of Experimental Psychology: General, 1975, 104, 268-294.

Cutring. J. E. Orienting tasks affect recall performance more than subjective impressions of ability to recall. Psychological Reports, 1975, 36, 155-158.

Hyde, T. S., \& Jenkins, J. J. Recall for words as a function of semantic, graphic, and syntactic orienting tasks. Journal of Verbal Learning and Verbal Behavior, 1973, 12, 471-480.

JENKINS, J. J. Can we have a theory of meaningful memory? In R. L. Solso (Ed.), Theories in cognitive psychology: The Loyola symposium. Hillsdale, N.J: Lawrence Erlbaum, 1974.

Postman, L. Short-term memory and incidental learning. In A. W. Melton (Ed.), Categories of human learning. New York: Academic Press, 1964.

Postman, L., \& Kruesi, E. The influence of orienting tasks on the encoding and recall of words. Journal of Verbal Learning and Verbal Behavior, 1977, 16, 353-369.

Rundus, D. Maintenance rehearsal and single-cued processing. Journal of Verbal Learning and Verbal Behavior, 1977, 16, $665-681$.

(Received for publication May 5, 1978.) 